\title{
A Comparative Study of Malayalam Literature and Paintings: Trajectories of Evolution
}

\author{
Sindu Antherjanam*
}

\section{Abstract}

Art and literature are part as well as a reflection of life. Literature and arts help to observe and interpret the world. They can also change the world. Visual arts stand in the forefront of knowledge dissemination. However the significance accorded to literature has never been given to painting. The paper traces how literature has always preceded and given more priority against painting and other visual arts form in the region of Kerala. This also goes with the fact that in discussing the history of arts, rural arts and artists are never discussed sufficiently. This is despite the fact that there is always a closer relationship between alphabets, scripts and paintings of various forms. The paper traces this close relationship to the earlier times when the scripts and written forms essentially evolved from hand drawings and stone carvings in the context of the south Indian language Malayalam. That the scripts and alphabets essentially evolved from those early pictographs should be a useful background to understand the relationship. The paper also marks the historical transitions in the Malayalam alphabets and scripts under various influences.

Keywords: Evolution of Malayalam Script, Vamozhi and Varamozhi, Modernity and Malayalam, Arts and Malayalam scripts, Raja Ravi Varma

*Sanatana Dharma College, Alappuzha, Kerala, India; dr.sinduantherjanam@gmail.com 


\section{Introduction}

This paper is an attempt to explore the close links between visual arts, especially paintings and drawings, and literature in the context of the south Indian language Malayalam. While there are ample historical accounts of both visual arts including drawings and literature as separate entities, there have not been several efforts that sketches the close links between them, both in the historical contexts and in the contemporary. In fact, as the paper will show, the intimate relation between the both can be traced to prehistory and to the periods when scripts and alphabets were still evolving. Interestingly this intimacy has remained very much in tact in the contemporary times too albeit in very different forms. This is the trend that paper is attempting to map. The paper covers large time periods albeit with regard to the sole concern around the connections between these two forms of creative expression.

Sound is a basic and natural form of language. The alphabet is the terminology for indicating the uttered sound, the letter. Varamozhi a common Malayalam phrase where ideas are expressed through painting - emphasises that registration of some technical lines is necessary for forming meaningful words. The lines represent terminology to form the letters or alphabet. The letters, commonly

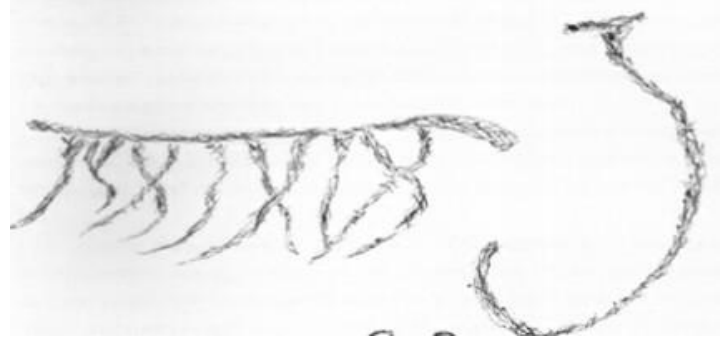

Fig 1 An instance of a $\operatorname{logogram}^{1}$ as given in the Viswa Vijnana Kosham (World Encyclopedia, Malayalam translation, 1972, p. 81)

called Aksharam in Indian languages under the influence of Sanskrit, are the written form of sounds pronounced by humans.

${ }^{1}$ A single written symbol that represents an entire word or phrase without indicating its pronunciation 
The sound is usually grasped through the senses. The five senses help usto receive and understand the meaning of the word. Aksharam- meaning $\mathrm{Na}$ Ksharam in Sanskrit - literally implies that which never loses, is eternal or everlasting. Thus the letter preserves the meaning invoked by the sound. The body of sound is formed with vowels or by the union of vowels and consonants. The physical structure of the letter is the alphabet and the 'soul' is pronunciation. As early as in 1913 Robert Caldwell had observed that it is hardly 4000 years since the practice of registering ideas with the help of sounds or signs of letters began (1913).

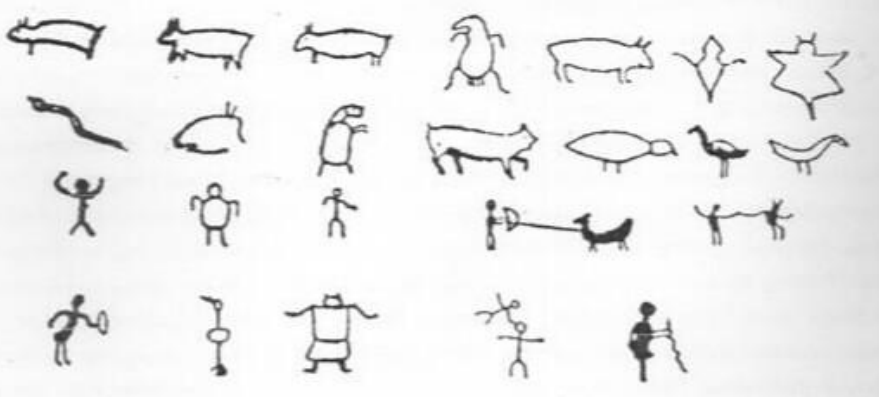

Fig 2 An instance of Pictogram². Source: Viswa Vijnana Kosham (World Encyclopedia, Malayalam translation, 1972, p. 81)

The ancient humans did not use the alphabets. The awareness of the figures of objects in nature made humans reconstruct them through paintings. These reflected their creativity. Pictography may be the beginning of 'writing' for the ancient humans. The pictures which were thus created to indicate the objects in nature are the primary forms of alphabet (Kurup, 1980). In the second stage, ideas were painted and depicted (ideography) in addition to the objects those which were visible to the naked eyes. Ideography was very much prominent in civilisations such as that existed in countries like Egypt, China, Babilona, Assyria etc. This was also a time when objects and ideas converged along meaningful lines; like for example the picture of sun and other elements in nature in

${ }^{2}$ Using graphic characters in the old forms of picture writing 
olden times also signified an idea of worship or a belief in the influence of that object on the humans' life on earth. Sun was not only an object in those old pictures but was also a symbol of unfathomable source of energy with an undisputable influence on human lives (Coomaraswamy, 1956).

\section{From paintings to writings}

The evolution of pictures gradually entered into a phase where alphabets were used for communicating sounds. The evolution of representing sounds from paintings to writings is a remarkable progress in human' civilization. David Diringer who had studied extensively about the emergence of language and its evolution through different stages had rightfully suggested in his book that "Alphabet is the key to the history of mankind" (1958/1996). The alphabets are the result of human's continued effort and attempt to develop and register human sounds and the abstract ideas and thought that those sounds often communicated. Gradually there emerged different alphabets in various languages at different times of civilisation.

The most ancient alphabet of India is 'Brahmi'. The historians note that there was a system of alphabet called 'Kharoshti Lipi' in India (Ramapizharadi, 1969). There is another opinion that it was the Sindhi Lipiseen in the engravings from the sites of Harappa and Mohanjo-daro that was later transformed and labelled 'Brahmi' (Ravivarma, Pracheena Kerala Lipikal). Around the same time Grantha Lipi evolved as asystem of alphabets in some of the regions in South India. The alphabet, used to write Sanskrit texts was called 'Aryaezhuthu' (first writing) or 'Granthakshara' (the textual alphabet) (Ravivarma, 1972).

\subsection{Ancient schemes of alphabets in Malayalam}

Although Malayalam in the modern forms is of recent origin, it existed from very old times along the side of the Tamil language, or as its variants. According to most of the historians of language, Malayalam originated from Tamil. In fact there is an academic consensus that Malayalam emerged from what was once called Koruthamil. The two systems of alphabet that prevailed in Malayalam language from olden times - spanning from $10^{\text {th }}-15^{\text {th }}$ 
century - were, one, Vattezhuthu (round-writing) and, two, Kolezhuthu (long-writing). There is proof of "using vattezhuthu till the $15^{\text {th }}$ century in the Chera and Pandya regions"(Ravivarma, 1972). Vattezhathu is signified by different names in different region like 'southern Malayalam, Nanamona, chera-pandyaezhuthu etc. The important feature of this genre is that letters used are usually presented in round form, vatta literally meaning in Malayalam round or circle (Lance, 1983).

Ravivarma observes that it should be called 'Vettezhuthu' instead of 'Vattezhuthu as Vatta-means round and vettu-mean cut. This is because the letters are written after cutting some of the parts. Anyhow Vattezhuthu has become prominent over periods of time. Kolezhthu in fact is the sub-division of Vattezhathu. Kol signifies the stick (Narayam in Malayalam) used to write. Thus Kolezhuthu has two meanings, for its shape, that is long and for the instrument used to write, that is the stick known as kol. The documents of Kolezhuthu are mostly registered in palm leaves.

Malayanma, a combination of Malayalam and Tamil, which followed in the scheme of Kolezhuthu (Ramapisharadi, 1969). The modern alphabet of Malayalam was brought into light by the King Swati Thirunal in the mid-19th century when Kolezhuthu slowly started changing for the convenience of the modern printing press. This was basically due to the technological transition from using the stick to the press where alphabets were then printed. Kolezluthu had a prominent place in the regions of Cochin and Malabar also. The Northern Malabar Muslims and Christians mostly used Kolezhuthu. The Mappila (Muslim) literature was mainly written in a mixed text of alphabet of Arabi-Malayalam. In fact in these regions the effect of technological transitions with the emergence of modern press was very least, and took much more time than in other regions. It is surprising to note that even ninety years back the people of Wayanad used Kolezhuthu (Ravivarma, 1972; Menon, 2016). According to some linguists the name Kolathu Nadu - the name by which Malabar was previously known itself was a result of the fact that Kolezhuthu was in popular use in those regions (Ramapizharadi, 1969; Menon, 2016). Malayanmalipi became popular only in Southern Kerala. 
Famous linguist Burnal had once observed how the cave characters in the ancient times had a direct transition to the alphabets in several South Indian languages (Menon, 2016). According to Ravivarma several south Indian alphabets including Malayalam Vattezhuthu have developed gradually from the north Indian script of Brahmi. These linguists thus are not in full agreement with the commonly held observation that Thunjath Ezhuthachan- popularly known in Kerala as the father of Malayalam language - was responsible for the development Malayalam alphabet. Another prominent observation that supports these linguists is that Granthaksharangal-also known as Arya Ezhuthukal-a very old form of Malayalam alphabet - were in practice since the $7^{\text {th }}$ century in South India. The very name Arya Ezhuthukal, according to these scholars, is sufficient sign of the early influence of the Sanskrit civilisation on these South Indian languages. Granthaksharangal turned into the alphabet of Malayalam by the $9^{\text {th }}$ Century. The emergence of 'Manipravalam' - a combination of Malayalam and Sanskrit - in $13^{\text {th }}$ century literature helped the Malayalam alphabet to survive and gain roots.

There were only 30 letters in the Dravida Bhasha. It consisted of 12 vowels and 18 consonants they are called Uyirezhuthu (Vowels) and Meyyezhuthu (Consonents) in Tamil respectively.

\section{Vowels A B C Cu D Du F G sF H Hm Hu \\ Consonants I N RSW X \] bce h f g d}

The modern Malayalam script contains 53 letters of which 23 were adopted from Sanskrit during different times. Below given chart depicts the modern scripts and their representation in the olden genres of scripts that was simultaneously used in the Tamil speaking regions. 
Sindu A Comparative Study of Malayalam Literature and Paintings

\begin{tabular}{|c|c|c|c|c|c|c|c|c|c|c|c|c|c|c|c|c|c|c|c|}
\hline \multirow[b]{3}{*}{$\infty$} & \multicolumn{7}{|c|}{ 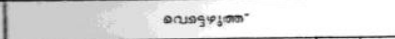 } & & \multicolumn{8}{|c|}{ ăدsersja } & \multicolumn{3}{|c|}{ Derteronos. } \\
\hline & \multirow[b]{2}{*}{ था } & \multirow[b]{2}{*}{21} & \multirow[b]{2}{*}{21} & \multirow[b]{2}{*}{21} & \multirow{2}{*}{\multicolumn{2}{|c|}{ धा 1}} & \multirow{2}{*}{\begin{tabular}{|l|}
$\infty$ \\
$n$
\end{tabular}} & $\infty$ & \multirow[b]{2}{*}{ us } & \multirow[b]{2}{*}{$n$} & \multirow[b]{2}{*}{21} & \multirow[b]{2}{*}{$m$} & \multirow[b]{2}{*}{$m$} & \multicolumn{3}{|c|}{ 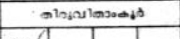 } & \multirow[b]{2}{*}{$\omega_{1}$} & \multirow[b]{2}{*}{$2 y$} & \multirow[b]{2}{*}{2} \\
\hline & & & & & & & & 4 & & & & & & $w$ & & & & & \\
\hline$\Rightarrow$ & $y$ y & of 28 & 623 & 28 & 36 & $3 y$ & 236 & $2 y$ & $y$ y & $y x$ & $2 y$ & $m$ & $\eta$ & $m$ & & & $y$ & $m$ & 20 \\
\hline 2 & $v^{2} 2$ & \begin{tabular}{l|l}
28 \\
\end{tabular} & 28 & $a^{2}$ & $\omega \omega$ & $\sigma \omega$ & హె & 2 & म2 & $P$ & హె & ณ & & क 56 & b) & -25 & 3 & 2 & 2 \\
\hline 97 & \begin{tabular}{l|l} 
भ० & 0 \\
\end{tabular} & .0 & $0 \cdot 0 \cdot$ & 60. & (1) & 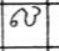 & & न & & ஓ & & & & के के & 33 br & & な & 2. & \\
\hline 2 & 22 & $2 \sqrt{2}$ & 2 & & e & & & 2 & 12 & & & $\sim$ & & $\approx 0$ & er & & e & & \\
\hline 27 & 20 & 2 & & & er & & & 2 & 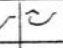 & & & $\sim$ & & $2-$ & & & er & & \\
\hline$\infty$ & 66 & 36 & $6 \gamma$ & & or & or & 6 & r $8 \gamma$ & 80 & & & & & & & & 6 & os & 6 \\
\hline$\infty$ & & & & & & & r & r & of & & & & & & & & 8 & 2 & \\
\hline$=\infty$ & $\psi$ & & & & & & & & & & & & & 8 & & & az & & \\
\hline$\rightarrow$ & $2 \cdot 2$ & 2 & & & 8 & 6 & & 6 & $\circlearrowleft$ & $2-$ & & 6 & & \begin{tabular}{|l|l}
2 & $\%$ \\
\end{tabular} & & & a & oy & \\
\hline$=3$ & & & & & & & & 3 & अ & N & & $\Leftrightarrow$ & $\simeq 6$ & ש & & & ov & (3) & \\
\hline 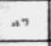 & & & & & & & & & & & & & & & & & & & \\
\hline$=$ & & & & & & & & & & & 3 & $\circ$ & $2 b$ & & & & & & \\
\hline & & & คบมุบ & $s \mathrm{~m}$ & & & & $=$ & & cossers & $s_{3} \mathrm{~mm}^{-}$ & & . & & & 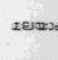 & & & \\
\hline$\Rightarrow$ & 7 & 7 & 7 & & & & & 7 & $\gamma$ & & $\gamma$ & & & 7 & $t$ & 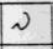 & $N$ & $N$ & 5 \\
\hline د & $\gamma$ & 7 & $\partial$ & $\gamma$ & & & & $z$ & $x$ & s & & & & $\gamma$ & $\Delta$ & $\gamma$ & & & \\
\hline 5 & $\cup$ & & & & $U$ & & & $U$ & & $v$ & & & & $\cup$ & & $v$ & & & \\
\hline$\infty$ & 3 & 3 & 3 & 3 & 8 & & & $B$ & 3 & & & $\beta$ & & $B^{\prime}$ & & 3 & & & \\
\hline 2 & U & 2 & 己 & 2 & U & U & & 己 & e & U & $\hat{\imath}$ & $\sim$ & 2 & e & & $e$ & 0 & & \\
\hline$\infty$ & 2 & ख्य & 2 & 2 & $q$ & & & ฯ & w & $m$ & ow & & & $n$ & -w & & 50 & & \\
\hline$\infty$ & y & कr) & 6 & 63 & 9 & 3 & 0 & 93 & & & & & & 63 & & & & & \\
\hline$m$ & 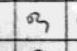 & an & Q & & 6) & s3 & 8 & 63 & 6 & ๑ & ? & & & $B$ & G & ๑ & ๆ & 9 & \\
\hline$\infty$ & 2 & 2 & 2 & 2 & 己 & & & $\mathcal{C}$ & () & 0 & $=$ & & & e & $e$ & $\because$ & 0 & & \\
\hline nn & $y$ & $y$ & 3 & 5 & & & & $y$ & $\infty$ & & & & & $\eta$ & $m$ & $m$ & $\rho$ & & \\
\hline 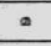 & 20 & 20 & 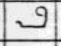 & $\infty$ & 2 & 22 & & e? & $\hat{v}$ & 10 & $\vartheta$ & 9 & & es & 0 & $\odot$ & 0 & & \\
\hline$\infty$ & $r$ & le & 2 & 2 & 2 & & & e & 2 & -2 & & & & e & & & & & \\
\hline 0 & 1 & 1 & 3 & 1 & 3 & 1 & & 1 & 1 & & & & & $\uparrow$ & & & & & \\
\hline 0 & 0 & 3 & 4 & & & & & $\Delta$ & I & $\cap$ & & & & $\Omega$ & $n$ & $?$ & & & \\
\hline e & o & & & & & & & 2 & 2 & 2 & $\sim$ & & & $\sim$ & & & & & \\
\hline a & 2 & 2 & 2 & & & & & & $\tau$ & 2 & $\sim$ & $\frown$. & & e & & ש & & & \\
\hline$\rightarrow$ & $\varphi$ & & & & & & & $\varphi$ & & & & & & 4 & & & & & \\
\hline 8 & or & & & & & & & ๆ & & & & & & 川 & & & 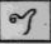 & & \\
\hline
\end{tabular}

Fig 3 Ancient Malayalam scripts ${ }^{3}$

${ }^{3}$ The narrow column on left end contains the modern Malayalam scripts. The second column represents the equivalent in Vattezhuthu, the third 


\section{Performing Arts}

Paintings are generally considered as capable of conveying ideas beyond time, space and language. From earlier times paintings have remained the most powerful devices for communication across cultures. There were paintings even in the Urns discovered from the Sindhu river banks. Similar to paintings' use of signs and gestures through a language of body was one very effective means for communicating stories in folk arts, especially in visual arts like Kathakali, Kootiyattam etc. The mudras meaning signs constitute an integral part of these art forms from their very beginnings. The mudras is an embodied language where signs with the help of hands and fingers were used to communicate the literal meaning of the verses being recited in the background to the audience. Thus we can understand that the theatre arts tried to transform the sound to a visual form. The visual aids can communicate even the toughest terms.

Traditionally Kerala has a number of arts in oral, written, spatial and performing forms. As in other cases, visual art also was patronised by kings, and wealthy people of the upper castes. But at the same time each village had its own problems for which they had their own solutions connected with ceremonies and rituals. Most of the activities were linked to the modes of agricultural works, distribution of products, taboos and sanctions bestowed upon by the members of authority of tribe/caste. For propitiating the revengeful Gods and Goddesses people decorated their bodies with colours and costumes for different ceremonies and rituals. This body decoration and making of mythical icons connected with the festivals of each folk were the art activities associated with the life of the village. When contemporary art or the 20 th century art of Kerala is looked at, these factors cannot be ignored. For Kerala the "gallery art" in the modern urban sense is very late and the "off gallery" art of the people is more rural oriented than urban. Technological, economic, cultural, sociological and religious factors and also different contexts divided the art forms, styles and execution. As in folklore tradition these village forms were not

column Kolezhuthu and the last column represents the equivalent in Maayanma scripts. 
termed art in the modern sense connected with the aesthetic of exhibition. These art forms of the people are even today practiced by the folk keeping it a living tradition.

\section{The period of Raja Ravi Varma}

Individual sensitivity and creativity were prized very high as against the collective work of the masses after the emergence of Raja Ravi Varma in the field urban-centered and west-oriented placement and evaluation of art encapsulated another milieu quite alienated from the traditional and conventional system of art work of Kerala. All over India this might have happened after the British people introduced their visual language of a personal signatory character instead of the collective one with intimate acquaintanceship of the masses. From the mid-19thcentury a tendency to refuse the prescribed formulas in visual art can be seen, but the traditional arts connected with religion, caste and ritual have remained the same. The oft-repeated forms, styles and themes confined to the allotted space of thought and place of work of the people were automatically changed when new ways of seeing the world with a political and sociological intention speed into it later (Kapur, 2000).

The art of Kerala for centuries was confined to the walls and floors of architecture and also to the face and the body of the performers. the fixed and conventionalised representation of prescribed themes on sanctioned spaces and places communities to execute the works in set patterns, and also to react to them in terms of particular dispositions of forms and colours. As in the case of society, visual art activity in general had this problem of stagnation in Kerala though different characteristics for each period divided according to the methodology of art history can be attributed to a certain extent. Almost all the mural paintings of Kerala are on the walls of temples, palaces, and Christian churches and all are thematically religious. The Walls, Sreekovil, and Gopuram were the prominent locations of paintings in temples. Among the Hindu Gods Vishnu, Siva, Ganesha, Sastha, Lakshmi, Parvati, Saraswathy and a variety of combinations of figures were the favourite themes for usual paintings. 

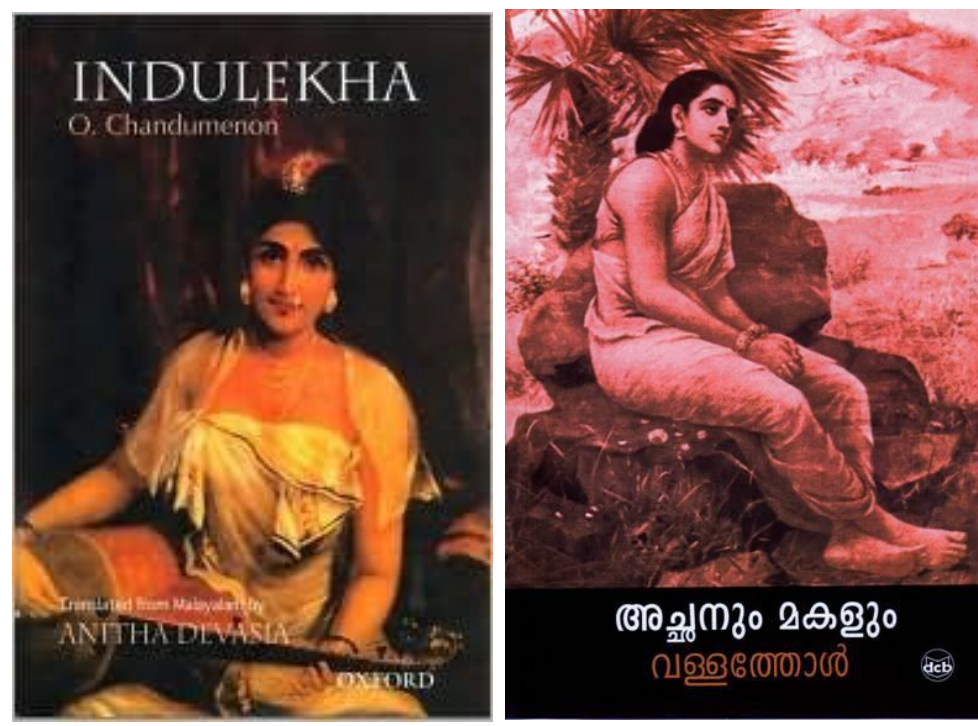

\section{Folk Paintings}

When other parts of India including Tamil region witnessed a conflict between Vaishnava and Saiva cults, Kerala had an amalgamation of these two in the figure of Harihara which become a prominent theme for mural paintings. Sastha, considered to be the son of Vishnu, who impersonated the female form Mohini and Siva, substantiated the fruit of the union of these diverse cults.

In the ancient Hindu system there are five basic colours (panchavarna - yellow, red, green, white and black) of which white is the wall itself and all other pigments are prepared from stones and leaves; the wall preparation is an elaborate process and on the specially prepared wall the picture is drawn first in line and then coloured, the iconography of most of which are based on Dhyanaslokas. Blue, one of the most powerful colours in nature is not seen in mural, floor, face/body paintings or the Kolams of Padayani though the sky and sea are observed as the blue infinity of human perception. In Kathakali, the characters Karkodakan and Bahukan of Nalacharitham have blue/black garments giving blue a chromatic connotation of poison.

The mural painting in Christian churches of Kerala have their own style derived from the iconographical and stylistic features of western pictorial forms, and some of them are as old as four 
centuries. The paintings in the Hindu temple/palaces are only in five colours while those in the churches have more colours to give an effect of illusion of reality and likeness. Though the perfect style of the Renaissance period cannot be seen most of the works have been executed, with a deliberate attempt to create perspective, but not in places easily seen by devotees.

Another tradition of painting is the preparation of diagrams using colour powders on the floor connected with rituals, beliefs and religion, a practice seen here also, as in the other parts of the country. Flawlines creating geometrical design with squares, circles and some floral patterns are diagrammatic talismans very much connected with daily life, belief and feminine authority of domestic protection. This tradition of visual ritual art practice of magical nature is transited by mother to daughter from generation to generation. Other floor diagrams/pictures executed again in connection with beliefs, rituals and religion by professionals of both sexes, but belonging to certain authorised communities, are figurative in nature (Coomaraswamy, 1956). Intertwined serpents, Kali, Vettakkorumakan and other figures with definite iconographic features done in five colours have specific purpose to ward off evil for which they are rendered in beautiful but frightening expressions. If the mural paintings have flat pictorial surface of perfect two dimensional characters at eye-level having no recession or thrust coming of space/figure, the floor pictures show a perspective of projecting up from the floor. Very sharp colours and compressed anatomy were used to get a feeling of bulging up from the floor with ferocious energy and terrifying facial/ formal, which are unlike the mural figures that are sober even in the most heroic act because of its classical stylisation as in Kathakali or Koodiyattom. These floor pictures were meant to propitiate gods/goddesses of unnamed fierceness and these figures are to be 'domesticated' to help the devotees by appearing them to direct their native wildness against the evil spirits devastating the humans. Not meant to exist permanently as the annihilating the evil have to go behind the mental curtain of social/individual domestic subconscious and they are erased immediately after the ritual. 


\section{Modernity and the modifications in Art and Literature}

From the mid-19th century, Kerala too, like in other parts of the country, albeit very slowly, was shedding the centuries-old customs and rituals. Many social and religious reformists spearheaded the movement towards a cultural reformation in which literature had a prominent part, but till recently very few people mentioned the contribution of visual art, perhaps due to the fact that this language was seenas a decorative item. The western way of showing the illusion of reality in art becomes a powerful communicative style in Raja Ravi Varma. When the art space sanctioned to each caste corresponding with closed social and cultural one slowly opened up with the emergence of Raja Ravi Varma, the crowded and closed compositional space of the mural painting could be replaced by the new pictorial awareness, and the new art and its style and technique become more public. As Narayana Guru, Ailyankali, Kelappan and others later tried to open up the closed places and roads to the public; pictorially Raja Ravi Varma opened it during the last decades of 19th century. As Chandu Menon, the contemporary of Ravi Varma opened up new vistas of social, cultural and aesthetic space in the form of the novel in literature as a result of his exposure to English spoken and written language, Ravi Varma too did the same through English visual language. This was a silent pictorial space of revolt analogous to the one in ChanduMenon's novel. But as the visual language was not a popular medium of communication in Kerala it was left unnoticed. With the introduction of English language and the communicative links like railway, postal service, etc. an integration of the land was achieved. But a relation of another nature could be achieved by the English visual language as it was retinal naturalism in quality and nature, that even uninitiated lay people could communicate and temple entry separating humans from gods even in the $21^{\text {st }}$ century, though the official declaration of temple entry was promulgated in 1936, one has to note the fact that pictorially, all these gods and goddesses have already took their abode in the houses of people of all castes/religions through these oleograph prints by Ravi Varma in the late $19^{\text {th }}$ century itself without the permission/Knowledge of the Brahmins and other upper castes. The scenic grace and excellence of the background in Ravi Varma's picture is analogous to the literary descriptions of 
forest scapes and mansions in the classical poetry though visually this was not shown till then in a naturalistic way corresponding to the 'realistic' narration in literature. When the figures of gods and goddesses were depicted in an atmosphere of romantic grandeur, the epic world in the imagination of the people got a Naturalistic representation in pleasing colour and forms.

Kerala got a populist theatre during the late $19^{\text {th }}$ century, and it was the same milieu that could be seen reflected on the art scene too, and a number of translations into Malayalam from Sanskrit and English appeared during the late 19th century. As a resultant extension, the famous translation of Sakunthalam by Kerala Varma Valiya Koyi Thampuran (1882) and some Shakespearean plays were staged in many parts of Thiruvananthapuram. The picturesque descriptions in the play could be seen in Ravi Varma's paintings of Sakunthalamthemes during the same decade, and people accepted it as a reality of correspondence between theatre and painting. The novels of C. V. Raman Pillai and Chandu Menon had also been staged as plays. The desire to see the familiar characters of literature on stage in flesh and blood was a phenomenon quite applicable to Ravi Varma's painting also. But the fact that the depiction of the same epic themes in paintings showed almost a 'theatrical text' was derived from a literary text. Most of the new theatrical ventures then, to create a realistic atmosphere used back-drops (curtains) with "painted scenery " which naturally attracted the spectators. Even to this day, G SankaraPillai has rightly noted that the backdrops become a part of the theatre language. Even Kathakali, the classical theatre was not spared, for there were attempts to use backdrops, as in the case of the same period, to create a realistic atmosphere.

In Kerala painting brought the common Malayalam prose language to the people the elite poetry handled by a few. Though it slowly started through printed translations of Bible and also through the printed texts of the poems Ezhuthachan, Poonthanam, Cherruserry and Kuchan Nambiar by the $19^{\text {th }}$ century, it promoted to acquire momentum in social activities as some protagonists tried to see things in an objective and democratic way. The oleograph prints of Ravi Varma's works also broke some taboos in the society silently as they democratically spread among people. 
Reformation in every branch of thought began, anda number of intellectuals, activists, religious protagonists, and reformers sprang up vehemently with new objectivity and social perspective. Sree Narayana Guru (1856-28), Chattambi Swami(1854-24), Ayyankali (1866-41), ChanduMenon(1847-99), Kumaran Asan (1873-24) were contemporaries of Ravi Varma. The horizon of the culturescape of Kerala was opened up and widened as it was seen in the background landscape of most of the works of RaviVarma.

MadhavaMenon created a lyrical nature of Kerala's atmosphere, climate, flora and fauna, humans and village life. To be in Santiniketan in the first half of the $20^{\text {th }}$ century and be a native painter without falling into simplistic approaches to technique and also to themes and moods was the healthy aspect of MadhavaMenon that could not be seen in many others. Madhava Menon's pictural images are lyrical when rendering nature as that of P Kunjiraman Nair in Malayalam poetry.

Intensive love and idiosyncratic attachment to nature and its every component made him a painter of unique quality which could not be taken up/followed/improvised by many others in Kerala. Madhava Menon, impressed by the thoughts of revivalism might have estimated state of the art in Kerala. His work with strong order and qualities of grammar of the visual language have resulted in meticulously articulated compositions reminding the subtle power of his observation. Painting somehow had a channel in the form of illustration for literature in periodicals. Camerarealism and Snap-shot realism dominated some popular publications like Malayala Manorama weekly but Jayakeralam, Mathrubhumi Weekly, and a few other journals which gave importance to illustration for short stories, novels and poems opened up a new transitionfor art. M. Bhaskaran, K. C. S. Paniker, M. V. Devan, A. S. Nair, Namboodiri and presently a number of others have made immensecontribution of their own with intricate characters of line and stylisation. Of late in the 90's some of the illustration by the younger generation are almost paintings of nearly independent existence. Linear and expressive qualities of drawing figures in the tradition of Madras school were the main features that made the illustrations of K. C. S. Paniker look innovative and rhythmic in the works be mainly did in 
Jayakeralam. Later when M. V. Devan did illustrations for literary works of Muhammad Basheeer and others he could take up the challenge following the masterly touch of K. C. S Paniker in such a way that those figures and compositions become as powerful a graphic attempt as the strong characterisation in the literary medium. Along with literature Devan's illustrations were also discussed, and a new awareness about art appeared in Kerala. A. S. Nair had his own style of figuration, modelling, shading and hatching. A stylisation A. S. Nair derived from graphic arts likewood cut/lino cut could be very expressive with its broken lines; some had the quality of water colour treatment with a wash effect. (Awash of diluted ink or water colour paint applied in combination with drawing is called pen and wash, wash drawing. Its effect long lasting). The spectacular graphics spread he did far O. V. Vijayan's Khasakkinte Ithihasam and sculptures effect in the figures for the novel Yayati stood distinctly in the art of illustration.

Literature-graphic relation from 1950's onwards invoked chances of seeing characters, situations, and emotions in linear images distanced very much from the repeatedly used 'realistic' drawings/photographs, and the artists and the intellectuals took it as a topic of discourse on par with the far advanced literature. Namboodiri's illustration became as famous as theliterary works themselves for which he did them. The liner quality of Namboodirican is seen on three axes mainly. (1) The vertical exaggeration for the male figures (2) The horizontal elongation for vehicles and animals (3) Voluminous exaggeration for female figures. Expressive gestures and distorted faces with suggestive poses brought in a new experience in the field of graphics/visual art.

During 1960's almost all branches of art all over India began a search for the identity of the local culture signs. Kerala had experienced through G. SankaraPillai and Kavalam Narayana Paniker, though attracted severe criticism. A few theatre artists tried to amalgamate Margi and Desi concepts of classic and folk art forms; and in literature, the presence of M. Govindan created a flutter in the intellectual circles. Visual art too had its contribution almost in the same direction as K. C. S. Paniker who excavated some of the signs and colours of local and somewhat obscure 
traditional visuals/culture (Ananthanarayanan, 1961). He created in his watercolours the localshape of Kerala with riverlets and country boats making the natural modulations of topography made visible the villager of Kerala of 1940's and 50's. His figurative works are from extensions derived from the general concept of anatomy. The anatomical features in 'Garden Series,' 'Red Interior' etc. have a particular character. The figural distortion in K.C.S Paniker can be divided at least into three.

1. The rhythm of the compressed limbs. "Mother and Child" has this language where the dwarfening and compressings of the limbs to create a pattern is obvious. Floor paintings of Kerala (Kalam) have a particular way of compressing the figures to give an impression of rising from the floor towards the beholder who has an angle of depression in looking at the picture. If that phenomenon is transformed on to the canvas at eyelevel, the figures can be somewhat similar to the distortion one can feel in "Mother and Child." By using the Indian concept of "Tribhangam and Bahubangam" and by shortening / dwarfing compressing the curvaceous forms, he could create and make an effect of figures seemingly rising directly or at rather an oblique angle.

2. The figural distortion is the next quality which is connected with the beauty of the seemingly stunted growth of limbs. Head, face, and eyes are exaggerated keeping hands and legs in diminution.

3. The third aspect of stylisation K. C. S. Paniker adopted was a derivation of the tubular quality of torso and limbs similar to the one familiar in the Dancing Girl figure of Indus valley period and also Chola sculptures.

Indian aestheticians have discussed the effect of distortion in connection with Hasya. One of the nine aesthetic sentiments that provoke laughter in literature and theatre; but figural distortion in art is not of that sort as it is mostly connected with expression or esteemed formal articulation. In Panikkar, figural distortion is individualistic, traditional, formal, historical and modern. Re- 
presentation, re-alignment and re-statement of the tradition in the art by him were almost parallel to what M Govindan did in literature, and G Sankara Pillai and Kavalam Narayana Panikkardid in the theatre. Modernity in Kerala was not onedimensional in growth or linear in progression. Colour, form, Script-like Scribbling in the series "Words and Symbols" were signs of a culture for connecting a tradition. It creates a painterly quality of pre-literacy and literacy levels of society by making evocative even the inactive pictorial blank space (Kapur, 2000; Kurup, 2006).

The 1960's are significant in the socio-political scene in the postindependence era; all the dreams of the youngsters nurtured in connection with the independent status of India were shattered during this decade. Those born in the second half of the 40 's were in the 1960's youths who were witness to the Chinese and Pakistan wars, the split of the communist party (in Kerala it had a strong cultural impact), the death of Jawaharlal Nehru, the split in the Congress party and the rise of Indira Gandhi to power establishing a dynastic rule by eliminating the stalwarts in the organisation. Disillusioned and alienated youngsters, Naxalism, Existentialism etc. manifested the intellectual milieu of the 1960's. Modern poetry in Malayalam was 'inaugurated' with the work of a few poets. Ayyappa Panikkar's Kurukshetram (1960, when it was first published the poem was considered radically experimental and a turningpoint in Malayalam poetry like The Waste Land in World Literature) received critical appraisal comparing it with "The Waste Land" of Elliot. N. N. Kakkad's poem 1963 brought in new images. Short story and novel got new dimensions through O. V. Vijayan, Kakkanadan, M. Mukundan, Madhavikutty, M. P. Narayanapillai, and others. 'Narabali,' the poem by P. Kunjhiraman Nair was of 1962. M. V. Devan too felt the situation and his "Homage to Hero" was a visual socio-political statement.

\section{Conclusion}

In the context of Kerala art perhaps K. P. Soman's work in Kadammanitta village and the Independence Golden Jubilee Monument in front of the secretariat in Thiruvananthapuram 1997 are the participatory public Art worth its name.Kadammanitta project is a public/participatory artwork giving a significatory 
sculptural text to the poetry of KadammanittaRamakrishnan. Most of the poems by Ramakrishnan are based on the mother Goddess element latentlyactive strongly at the social and personal subconscious level, and also the male/father prowess vigorously surrounding the Kadammanitta Kavu. Kavu literally meaning grove is a cluster of trees that become the abode of the mother goddess, who, without any roof above her head and walls around her, lives in nature (Nana Durga implies the wet Durga, and Vana Durga implies Durga in the forest) in the Dravidian linkage of the culture. This concept, culture, and space were usurped later by the Aryamised/Sanskritised practices, as a result of which the open-air Durga was enclosed in the temple, and even entry for the people to her abode was restricted imposing different rules based on caste, religion and dress code. The 'sculptural grove' is a miniature indicator of the land and poetry. The slop from the top of the simulated sculpture grove to the bottom steps of the top of the clustered forms signified an apparent river flow. Being a participatory work, the villagers along with Soman have sculpted figures and written the lines of Ramakrishnan's poems there; and this Panchayat sponsored work was named by the villagers 'Kavyasilpa' affectionately. This site sculpture is theatre too, like the Kadammanitta Kavu that becomes a theatrical space of performance during the Padayani, when people participate and perform with painted forms of different characters and manifestation of mother Goddess accompanied by songs. This project begins in 1993 and completed in 2001. Painting is relevant even today as an effective form of communication and learning. The change in paintings influenced all fine-arts.

\section{References}

Ananthanarayanan, M. (1961). K.C.S. Panikkar. New Delhi: Lalit Kala Academy.

Arnold, H. (1982). The social history of art. London: Routledge and Kegan. Coomaraswamy, A. (1956). Transformation of nature in art. Dover, USA.

Diringer, D. (1956/1998). The book before printing: Ancient, medieval and oriental. New York: Dover Publications.

Kapur, G. (1989). Ravi Varma's representational dilemmas of a nineteenth century indian painter. Journal of Arts \& Ideas, 17-18. 
Sindu A Comparative Study of Malayalam Literature and Paintings

Kapur, G. (2000). When was modernism. New Delhi: Tulika.

Kramrisch, S. (1983). The forms of Kerala paintings: The splendours of Kerala. Bombay: Marg.

Krishnachaithanya. (1994). A History of Indian Paintings-Mural tradition. New Delhi: Abhinav Publications.

Kurup, K.K.N. (1980). Arya Dravida ghadagangal malabarile nadankalayil (Trans. The Traces of Aryan and Dravidian elements in the Folk Arts of Malabar). Thrissur: H\&C Publications.

Kurup, K.K.N. (2006). Nadan Kalakalum Acharangalum (Mal: Traditions and Folk Arts). Thrissur: H\&C Publications.

Lance, D. (1983). The metal art of the Cheras - Splendours of Kerala. Bombay: Marg.

Menon, V. (2016). Bharatheeya Kala Charitram (Mal: History of Indian Arts). Thrissur: Sahitya academy.

Ramapizharadi, P. (1969). Vattazhuthum Kolezhuthum (Mal: Round and Long Writing). Kottayam: Mathrubhumi.

Ravivarma, L. A. (1972). Pracheena Kerala Lipikal (Ancient Kerala Scripts). In Malayalam World Encyclopedia (Vol. 1). Thiruvananthapuram: Government of Kerala.

Robert, C. (1913/1998). A comparative grammar of the Dravidian or south Indian family of languages (Trans. S. K. Nair). Thiruvananthapuram: Kerala Bhasha Institute.

Sivaramamurthy. (1979). The art of Indian symbols in Indian art Splendors of Kerala. Bombay: Marg publications. 